\title{
Sedation for colonoscopy: A double-blind comparison of diazepam/meperidine, midazolam/fentanyl and propofol/fentanyl combinations
}

\author{
MARK A KOSTASH MD FRCPC, RICHARD JOHNSTON MD FRCPC, RJ BAILEY MD FRCPC, \\ ELSIE M KONOPAD RN MN, LORRAINE P GUTHRIE RN
}

MA KOSTASH, R JOHNSTON, RJ BAILEY, EM KONOPAD, LP GUTHRIE. Sedation for colonoscopy: A double-blind comparison of diazepam/meperidine, midazolam/fentanyl and propofol/fentanyl combinations. Can J Gastroenterol $1994 ; 8(1): 27-31$. Rate of recovery and incidence of complications were compared among three intravenous sedation techniques for colonoscopy. Sixty patients were randomized to receive diazepam and meperidine, midazolam and fentanyl, or propofol and fentanyl with a continuous infusion of propofol. Patients were sedated to a standard end-point using a double-blinded technique. There were no differences in rate of recovery or incidence of minor side effects among the three groups. The techniques were equally effective in providing sedation and analgesia for colonoscopy. All groups developed significant oxygen desaturation measured by continuous pulse oximetry. Over $20 \%$ of patients required supplemental oxygen due to persistent desaturation below $85 \%$ following administration of sedatives. The authors conclude that oxygen should be administered to all patients undergoing colonoscopy.

Key Words: Colonoscopy, Complications, Hypoxemia, Oximetry, Pain, Sedation

Sédation pour colonoscopie : comparaison à double insu de diazépam-mépéridine, midazolam-fentanyl et de propofol-fentanyl, en association

RÉSUMÉ : Le taux de récupération et la fréquence des complications ont été comparés en rapport avec trois techniques intraveineuses de sédation pour la colonoscopie. Soixante patients ont été randomisés afin de recevoir du diazépam et de la mépéridine, du midazolam et du fentanyl ou du propofol et du fentanyl, avec une perfusion continue de propofol. Les patients ont été sédationnés pour

Royal Alexandra Hospital, Departments of Anaesthesia and Gastroenterology, in affiliation with the University of Alberta Hospitals, Edmonton, Alberta

Correspondence and reprints: Dr Mark Kostash, Department of Anaesthesia, Calgary

General Hospital, 841 Centre Avenue East, Calgary, Alberta T2E OAl

Received for publication December 15, 1992. Accepted April 22, 1993
OlONOSCOPY CAN BE A PAINFUl procedure due to stimulation of sensitive viscera. Discomfort is increased in certain colonic diseases and when the endoscopist is inexperienced. While some physicians perform colonoscopy in fully awake patients, sedation using a combination of benzodiazepine and a narcotic usually is necessary $(1,2)$. To tolerate the procedure, patients often require high doses of sedatives, which may depress the respiratory and cardiovascular systems, resulting in serious sequelae. While it is suggested that many new medications provide advantages over traditional drugs, there is a need for studies to use a standard end-point of sedation and blinding of agents to obtain meaningful comparisons. This study compares three sedation techniques for reliability of sedation, incidence of complications and rate of recovery.

\section{PATIENTS AND METHODS}

The study was a prospective, randomized, double-blind clinical trial. Approval was obtained from the Royal Alexandra Hospital Ethical Review Committee. Sixty consecutive patients scheduled for elective colonoscopy 
obtenir un paramètre standard à l'aide d'une technique à double insu. Aucune différence n'a été notée sur le plan du taux de récupération ni sur le plan de la fréquence d'effets secondaires mineurs entre les trois groupes. Les techniques se sont révélées tout aussi efficaces à fournir sédation et analgésie pour la colonoscopie. Tous les groupes ont présenté une désaturation d'oxygène importante, mesurée par l'oxymétrie de pouls continue. Plus de $20 \%$ des patients ont nécessité un supplément d'oxygène à cause d'une désaturation persistante sous les $85 \%$ suite à l'administration des sédatifs. Les auteurs en concluent que l'oxygène doit être administré à tous les patients qui subissent une colonoscopie.

\section{TABLE 1}

\section{Sedation scale}

\begin{tabular}{cc}
\hline Level 1 & Fully awake and oriented \\
level 2 & Drowsy \\
Level 3 & $\begin{array}{c}\text { Eyes closed but rousable to } \\
\text { command }\end{array}$ \\
Level 4 & $\begin{array}{c}\text { Eyes closed but rousable to } \\
\text { mild physical stimulation }\end{array}$ \\
Level 5 & $\begin{array}{c}\text { Unrousable to mild physical } \\
\text { stimulation }\end{array}$
\end{tabular}

Based on reference 4

agreed to participate and informed consent was completed.

Exclusion criteria included age under 18 years, allergy to any study medication, pregnancy or inability to complete a questionnaire in English following the procedure. All patients were monitored using continuous pulse oximetry (oxygen saturation - $\mathrm{SpO}_{2}$ ) (Nonin Medical 8604D Pulse Oximeter) and oscillometric blood pressure (Critikon Dinamap Vital Sign Monitor). A continuous intravenous infusion was started in each patient. Subjects were randomized (using random numbers) by a pharmacist to one of three sedation groups: group D - diazepam plus meperidine; group $\mathrm{M}-\mathrm{mi}$ dazolam plus fentanyl; and group P propofol plus fentanyl. The study medications were blinded by diluting diazepam, midazolam and propofol to equipotent concentrations in intralipid, the carrier for propofol (3). Diazepam was diluted to $1 \mathrm{mg} / \mathrm{mL}$, midazolam to $0.5 \mathrm{mg} / \mathrm{mL}$, and propofol was used in the usual $10 \mathrm{mg} / \mathrm{mL}$ concentration. Meperidine $50 \mathrm{mg} / \mathrm{mL}$ and fentanyl $50 \mu \mathrm{g} / \mathrm{ml}$ were considered equipotent.

Drugs were administered in a predetermined volume per kilogram and total drug dosages were later calculated. Patients received $0.07 \mathrm{~mL} / \mathrm{kg}$ of the

TABLE 2

Aldrete recovery score

\begin{tabular}{ll}
\hline Activity* $^{*}$ & 2: four extremities \\
& 1: two extremities \\
& 0: no extremities \\
Respiration & 2: deep breath/ cough \\
& 1: dyspnea/shallow \\
& breath \\
Circulation ${ }^{\dagger}$ & 2: apneic $\pm<20 \mathrm{mmHg}$ \\
& 1: \pm 20 to $50 \mathrm{mmHg}$ \\
& $0: \pm>50 \mathrm{mmHg}$ \\
Consciousness & $2:$ fully awake \\
& 1: arousable on calling \\
& $0:$ not responding \\
Colour & 2: normal \\
& 1: pale, dusky, blotchy \\
& $0:$ cyanotic
\end{tabular}

Total Aldrete score (out of 10)

Based on reference 5. "Spontaneous or on command; ${ }^{\dagger}$ Preoperative blood pressure

white sedative and $0.03 \mathrm{~mL} / \mathrm{kg}$ of the clear narcotic solution. These doses were decreased by one-third in patients over 65 years old. Patients were sedated to a level 3 or 4 on a five-point sedation scale described by MacKenzie (Table 1) (4).

Once sedated, a continuous infusion of propofol was initiated in group $\mathrm{P}$ at $50 \mu \mathrm{g} / \mathrm{kg} / \mathrm{min}$ via a Baxter AS20GH infusion pump. Intralipid was substituted in groups $\mathrm{D}$ and $\mathrm{M}$ as a control. If patient tolerance of the procedure was inadequate, one-third of the original dose of both narcotic and sedative was administered as supplementation, and the infusion rate was doubled.

Vital signs were recorded at baseline and every 5 mins until the end of the procedure. Initially, all patients breathed room air. Oxygen was administered if $\mathrm{SpO}_{2}$ dropped below $85 \%$ and remained there for longer than $15 \mathrm{~s}$.

Following colonoscopy, infusions were discontinued and patients transported to the out-patient recovery room. Stable vital signs and an $\mathrm{SpO}_{2}$ of $90 \%$ or greater on room air was required prior to transfer. On arrival in recovery and every 15 mins thereafter, Aldrete scores (5) were calculated (Table 2). This was continued for 90 mins or until three perfect scores of 10 were achieved. Length of time to eye opening, response to command, orientation and return to level 1 sedation were recorded. One hour after arrival in recovery, subjects completed a questionnaire recording incidence of side effects (dizziness, nausea, blurred vision, headache, poor concentration or drowsiness at discharge).

All staff participating in the study were surveyed after each procedure to assess the adequacy of sedation and to predict which combination of agents had been used.

Analysis of variance was used to compare the groups for recovery times and vital signs, and a test of proportions was used to compare side effects and complications. $\mathrm{P}<0.05$ was considered significant for all analyses.

\section{RESULTS}

There were no differences in patient demographics or indication for the procedure among the three study groups (Table 3). The most common indications were inflammatory bowel disease, a history of polyps or rectal bleeding. Fifty-seven patients participated in the study. One patient from each sedation group was withdrawn because of intolerance to the procedure despite administration of all drugs provided by pharmacy; supplemental diazepam was administered to these patients. There were no significant differences in vital signs among sedation groups at baseline, following sedation or during the procedure. No patient required atropine or vasoactive agents for bradycardia, hypertension or hypotension.

On average, group D patients received $0.12 \mathrm{mg} / \mathrm{kg}$ diazepam and 2.0 $\mathrm{mg} / \mathrm{kg}$ meperidine. Group $\mathrm{M}$ received $0.07 \mathrm{mg} / \mathrm{kg}$ midazolam and $2.2 \mu \mathrm{g} / \mathrm{kg}$ fentanyl. Group P received $1.3 \mathrm{mg} / \mathrm{kg}$ propofol and $2.2 \mu \mathrm{g} / \mathrm{kg}$ fentanyl. Peak infusion rate of propofol in group $\mathrm{P}$ av- 
TABLE 3

Patient demographics

\begin{tabular}{lcccc}
\hline & Diazepam & Midazolam & Propofol & $P<0.05$ \\
\hline Age (years) & $48.3 \pm 18.2$ & $40.9 \pm 15.1$ & $45.8 \pm 18.4$ & NS \\
Weight (kg) & $70.2 \pm 12.3$ & $71.4 \pm 12.3$ & $68.4 \pm 14.8$ & NS \\
$\begin{array}{l}\text { Sex (female/ } \\
\text { male) }\end{array}$ & $9 / 10$ & $10 / 9$ & $10 / 9$ & NS \\
Duration (mins) & $22.5 \pm 10.5$ & $22.3 \pm 10.6$ & $23.4 \pm 9.4$ & NS \\
Baseline SpO 2 & $96.9 \pm 1.4$ & $96.6 \pm 1.8$ & $96.6 \pm 1.7$ & NS \\
Ps (mmHg) & $134.3 \pm 21.5$ & $130.2 \pm 13.8$ & $137.2 \pm 26.9$ & NS \\
Pd (mmHg) & $75.4 \pm 12.2$ & $74.9 \pm 9.3$ & $76.3 \pm 11.5$ & NS \\
Px (mmHg) & $95.0 \pm 14.5$ & $93.3 \pm 10.1$ & $96.6 \pm 15.6$ & NS \\
Pulse & $76.9 \pm 12.3$ & $77.9 \pm 11.0$ & $79.9 \pm 10.5$ & NS \\
\hline
\end{tabular}

$n=19$ in all groups. Values are expressed as mean $\pm S D$. NS Not significant; Pd Diastolic blood pressure; Ps Systolic blood pressure: Px Mean blood pressure
TABLE 4

Drug dosages by treatment group

\begin{tabular}{lccc}
\hline & Diazepam & Midazolam & Propofol \\
\hline Total drug dosages & & & \\
Sedative $(\mathrm{mg} / \mathrm{kg})$ & $0.12 \pm 0.04$ & $0.07 \pm 0.02$ & $1.3 \pm 0.29$ \\
Narcotic $\left(\mathrm{mg} / \mathrm{kg}^{*}\right.$, & $2.0 \pm 0.50^{*}$ & $2.2 \pm 0.56^{\dagger}$ & $2.2 \pm 0.48^{\dagger}$ \\
$\left.\mu \mathrm{g} / \mathrm{kg}^{\dagger}\right)$ & & & \\
Propofol infusion & - & - & $76.5 \pm 30$ \\
$\quad(\mu \mathrm{g} / \mathrm{kg} / \mathrm{min})$ & & &
\end{tabular}

\begin{tabular}{|c|c|c|c|}
\hline \multicolumn{4}{|c|}{ Average dose and cost for a $70 \mathrm{~kg}$ patient } \\
\hline Sedative & $8.65 \mathrm{mg}$ & $4.99 \mathrm{mg}$ & $90.7 \mathrm{mg}$ \\
\hline Narcotic & $143 \mathrm{mg}$ & $154 \mu \mathrm{g}$ & $151 \mu \mathrm{g}$ \\
\hline Propofol infusion & - & - & $125 \mathrm{mg}$ \\
\hline Total cost & $\$ 1.26$ & $\$ 4.52$ & $\$ 12.44$ \\
\hline
\end{tabular}

eraged $76.5 \mu \mathrm{g} / \mathrm{kg} / \mathrm{min}$. The analgesic dosages used were similar to those generally used by this endoscopist (RJB).

Recovery time among the three groups showed no statistical differences (Table 5). The standard deviation for each variable was as large, or larger, than the mean. Eye opening and orientation occurred within 6 mins of the end of the procedure in each sedation group. There was also a tendency for patients to open their eyes and become oriented more quickly in group $\mathrm{M}$. There was also a trend toward Aldrete scores of 10 being achieved more quickly in the propofol group. With larger groups, results might have reached statistical significance.

Minor side effects were common (Figure 1). There tended to be fewer side effects in the propofol group, but this difference was not significant. Forty per cent of patients in each group experienced moderate to severe pain during the procedure. Despite the frequent complaint of pain, only $15 \mathrm{pa}$ tients were dissatisfied with the adequacy of sedation - eight of these patients were in the midazolam group. Only one patient in each group was assessed to be sedated inadequately by the endoscopist performing the procedure.

There was a significant decrease in oxygen saturation in all groups following intravenous sedation (Figure 2). $\mathrm{SpO}_{2}$ fell from a baseline of over $96 \%$ in all groups to 79 to $83 \%$. Only six of 57 subjects remained above 90\% throughout the entire colonoscopy

\section{TABLE 5}

Recovery times (in mins)

\begin{tabular}{lcccc}
\hline & Diazepam & Midazolam & Propofol & P $<0.05$ \\
\hline Eye opening & $5.3 \pm 9.6$ & $1.6 \pm 2.7$ & $4.7 \pm 5.9$ & NS \\
Response to command & $1.9 \pm 2.3$ & $1.5 \pm 2.7$ & $3.8 \pm 4.1$ & NS \\
Oriented & $5.8 \pm 9.3$ & $3.5 \pm 4.1$ & $5.3 \pm 5.7$ & NS \\
Aldrete score of 10 & $24.5 \pm 24.4$ & $25.0 \pm 29.9$ & $13.3 \pm 15.7$ & NS \\
Return to level 1 sedation & $30.4 \pm 29.0$ & $30.5 \pm 33.7$ & $23.5 \pm 24.4$ & NS \\
\hline
\end{tabular}

Values are expressed as mean \pm SD. NS Not significant

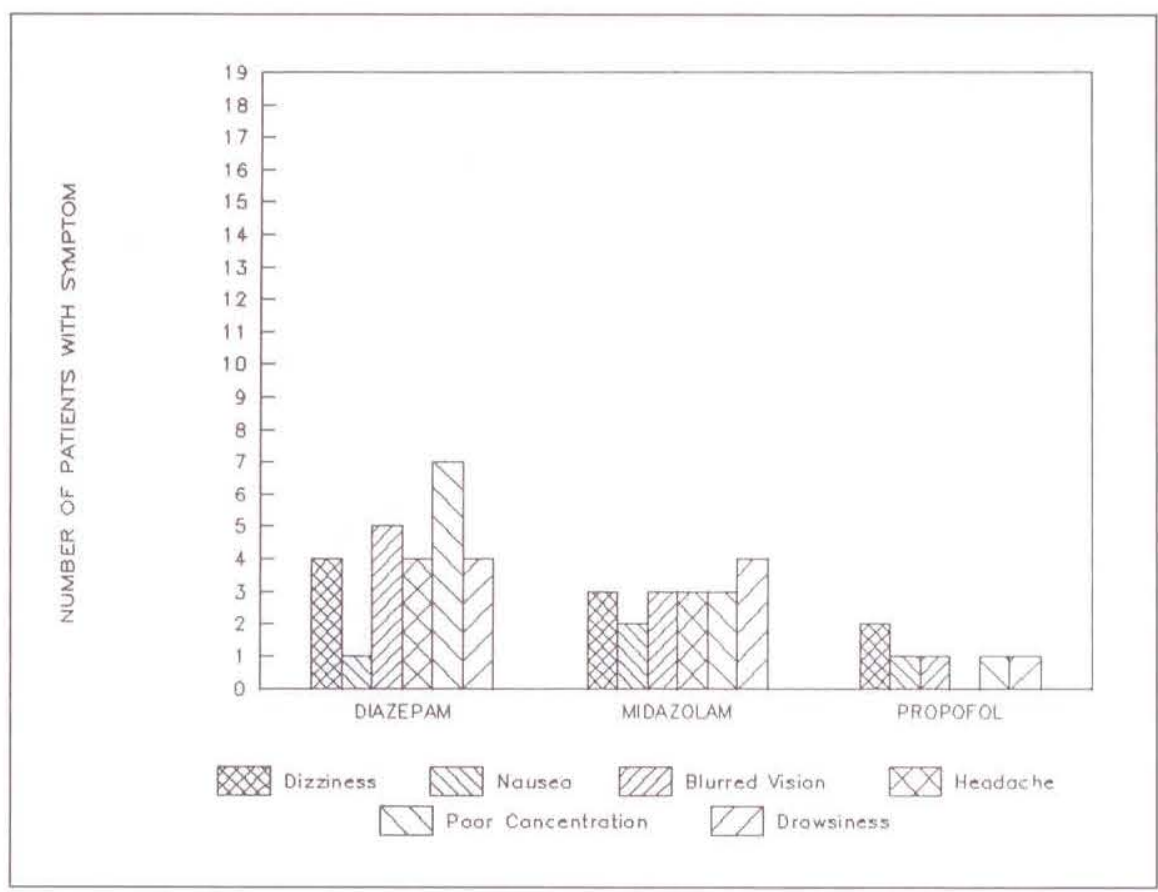

Figure 1) Summary of minor side effects associated with each study group

(Figure 3). Two-thirds of patients fell below a saturation level of $85 \%$, and 12 required low-flow supplemental oxygen to raise the saturation back above $85 \%$. Oxygen was required in a significantly higher proportion of patients in the propofol group $(\mathrm{P}<0.05)$.

Predictions of the agents used by the endoscopist, assistant, investigator, research nurse and recovery room nurses 


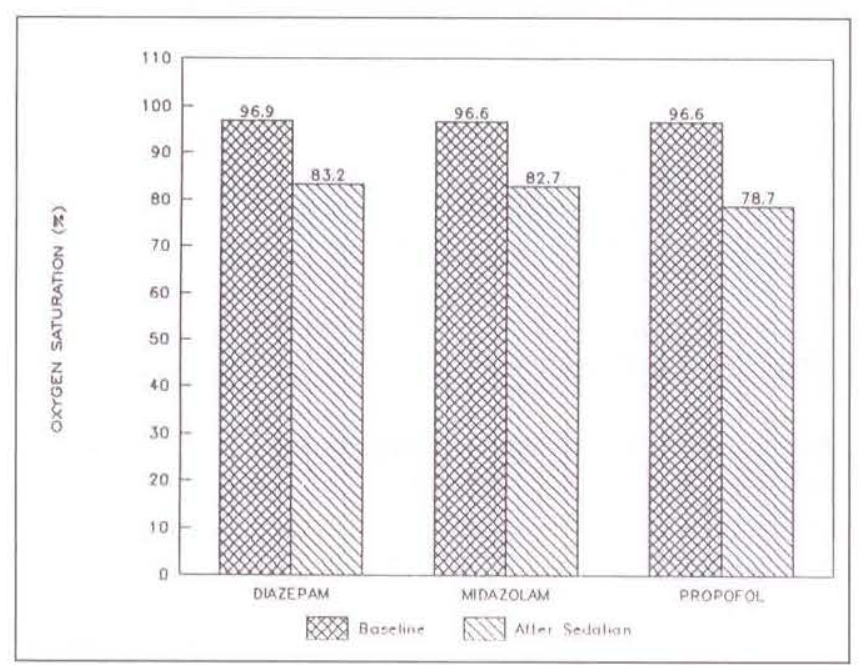

Figure 2) Decrease in oxygen saturation in each group following intravenous sedation

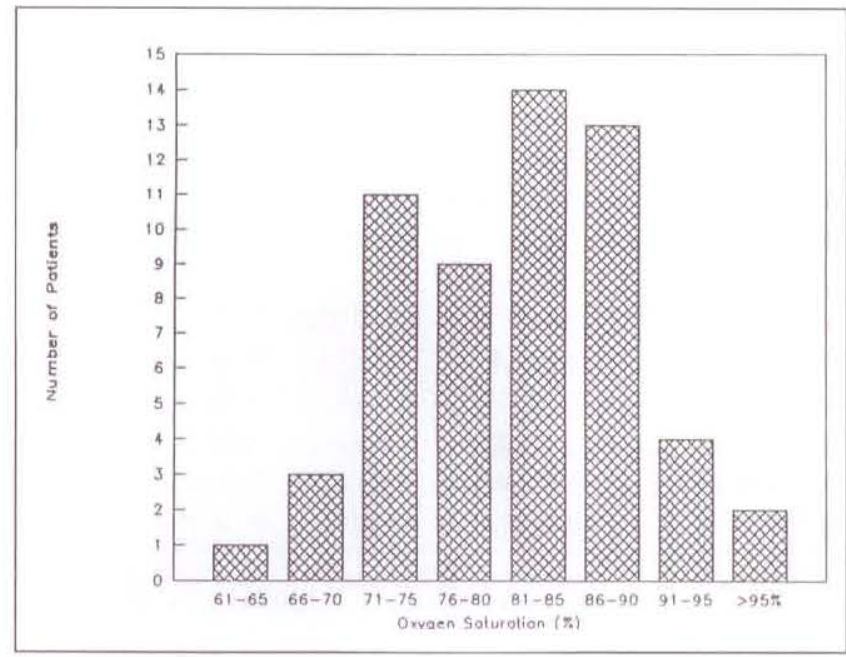

Figure 3) Lowest oxygen saturation throughout the entire colonoscopy were correct $29 \%$ of the time overall. There was no difference in accuracy among the three sedation groups. However, the research nurse was correct nearly twice as often as the assistant endoscopist (37.3\% versus $20.8 \%$ ).

\section{DISCUSSION}

Although new intravenous agents are thought to provide better sedation and more rapid recovery than traditional drugs, no randomized, doubleblind trials using a standard end-point have been performed. Unconscious bias and subjective ratings by investigators can result in unwarranted conclusions concerning efficacy and safety. The objective of this study was to compare three sedation techniques to find which one provides the best conditions for colonoscopy, with the fewest complications and fastest recovery.

While all techniques provided adequate conditions in equipotent dosages, both midazolam and propofol, when combined with fentanyl, demonstrated no advantage over the more established and less expensive diazepam-meperidine combination. A higher proportion of patients in the midazolam group felt the sedation was inadequate, and more patients receiving propofol required oxygen (compared with the diazepam group). Any small benefit in recovery time was nullified by side effects and complications. Others have found no faster recovery after midazolam (6-9) despite its shorter elimination half-life of 1.7 to $4 \mathrm{~h}$ (compared with 24 to $57 \mathrm{~h}$ for diazepam) (10). While Valtonen and colleagues (11) reported a faster recovery from propofol anesthesia and sedation compared with diazepam and midazolam, our study did not support this finding. The contribution of narcotic agents to residual sedation may explain why there was no statistical difference found in recovery times among the three groups. Use of an ultrashort acting narcotic, such as alfentanil, might allow separation of the effects from narcotic and sedative agents by avoiding residual narcosis at the end of the procedure.

Midazolam has been used extensively in endoscopy suites in North America for sedation prior to endoscopy. However, it is not an analgesic when used for sedation during painful procedures, a narcotic must usually be added.

Risks of midazolam or propofol plus narcotic combinations, related to synergistic depression of hypoxic ventilatory drive, recently have been reported $(3,12)$.

\section{CONCLUSIONS}

The authors have demonstrated that hypoxemia frequently occurs with all sedation techniques when oxygen is not routinely administered. One could argue that such hypoxemia is transient and should not cause damage in young, healthy individuals, but many patients undergoing endoscopy are neither young, nor healthy. Deaths have been reported in endoscopy suites in North America and Europe $(13,14)$. Premedication, underlying cardiopulmonary disease and advanced age have been cited as risk factors for complications. Other investigators have suggested routine use of oxygen during endoscopic procedures $(6,15)$. While only 12 of 57 patients were given supplemental oxygen, this was due to the broad guidelines used at this institution. Oxygen is administered only if the saturation drops and remains below $85 \%$. In other patient care areas where sedatives are administered, namely the operating room and intensive care, supplemental oxygen always is administered to keep the $\mathrm{SpO}_{2}$ above 90 to $92 \%$. Since 51 of 57 patients dropped below a saturation of $90 \%$, at least transiently, the authors recommend that all patients undergoing colonoscopy receive supplemental oxygen.

\section{REFERENCES}

1. Daneshmend TK, Bell GD, Logan RFA. Sedation for upper gastrointestinal endoscopy: Results of a nationwide survey. Gut 1990;32:12-4.

2. Hartke RH, Gonzalez-Rothi RJ, Abbey NC. Midazolam-associated alterations in cardiorespiratory function during colonoscopy. Gastrointest Endosc 1989;35:232-8.

3. Sebel PS, Lowdon JD. Propofol: A new intravenous anesthetic.

Anesthesiology 1989;71:260-77.

4. MacKenzie N, Grant IS. Propofol for 
intravenous sedation. Anaesthesia 1987;42:3-6.

5. Aldrete JA, Kroulik D. A postanesthetic recovery score. Anesth Analg 1970;49:924-34.

6. Bell GD, Morden A, Coady T, Lee J, Logan RFA. A comparison of diazepam and midazolam as endoscopy premedication assessing changes in ventilation and oxygen saturation. $\mathrm{Br}$ Clin Pharmacol 1988;26:595-600.

7. Sanders LD, Davies-Evans J, Rosen M, Robinson JO. Comparison of diazepam with midazolam as iv sedation for outpatient gastroscopy. $\mathrm{Br}$ J Anaesth 1989;63:726-31.

8. Berggren L, Eriksson I, Mollenholt P, Wickbom G. Sedation for fibreoptic gastroscopy: A comparative study of midazolam and diazepam. Br J Anaesth 1983;55:289-96.

9. Lewis BS, Shlien RD, Waye JD, Knight RJ, Aldoroty RA. Diazepam versus midazolam (versed) in outpatient colonoscopy: A double-blind randomized study. Gastrointest Endosc 1989;35:33-6.

10. Reeves JG, Fragen RJ, Vinik HR, Greenblatt DJ. midazolam:

Pharmacology and uses. Anesthesiology 1985;62:310-24.

11. Valtonen M, Salonen M, Forssell H, Scheinin M, Viinamaki O. Propofol infusion for sedation in outpatient oral surgery. Anaesthesia 1989;44:730-4.
12. Alexander CM, Gross JB. Sedative doses of midazolam depress hypoxic ventilatory responses in humans. Anesth Analg 1988;67:377-82.

13. Bailey PL, Pace NL, Ashburn MA, Moll JWB, East KA, Stanley TH.

Frequent hypoxemia and apnea after sedation with midazolam and fentanyl. Anesthesiology 1990; 73:826-30.

14. Hart R, Classen M. Complications of diagnostic gastrointestinal endoscopy. Endoscopy 1990;22:229-33.

15. Simon IB, Lewis RJ, Satava RM. A safe method for sedating and monitoring patients for upper and lower gastrointestinal endoscopy. Am Surg 1991;57:219-21. 


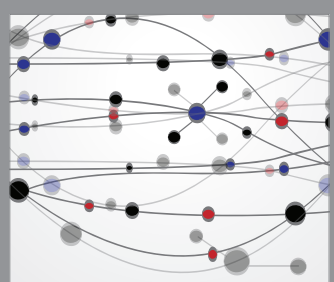

The Scientific World Journal
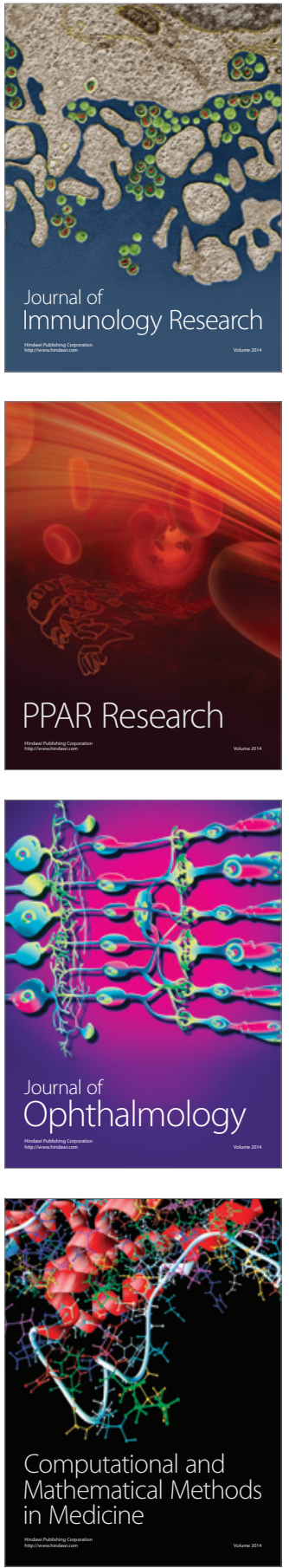

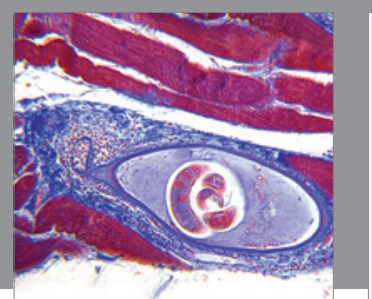

Gastroenterology Research and Practice

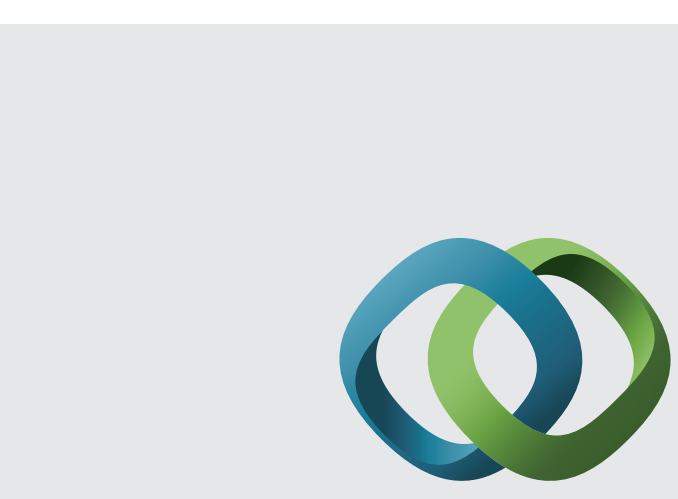

\section{Hindawi}

Submit your manuscripts at

http://www.hindawi.com
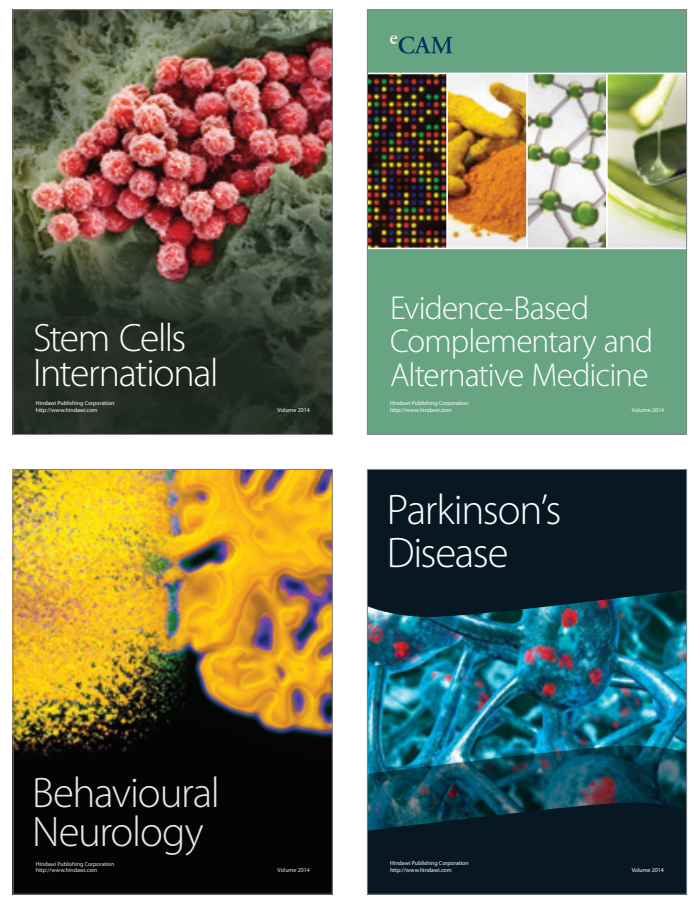
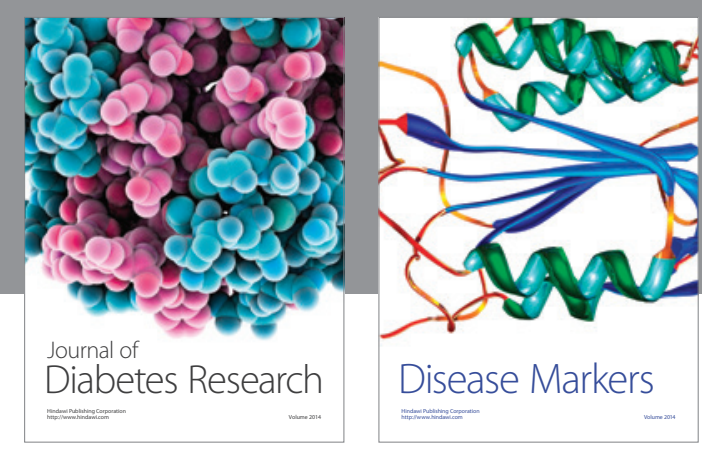

Disease Markers
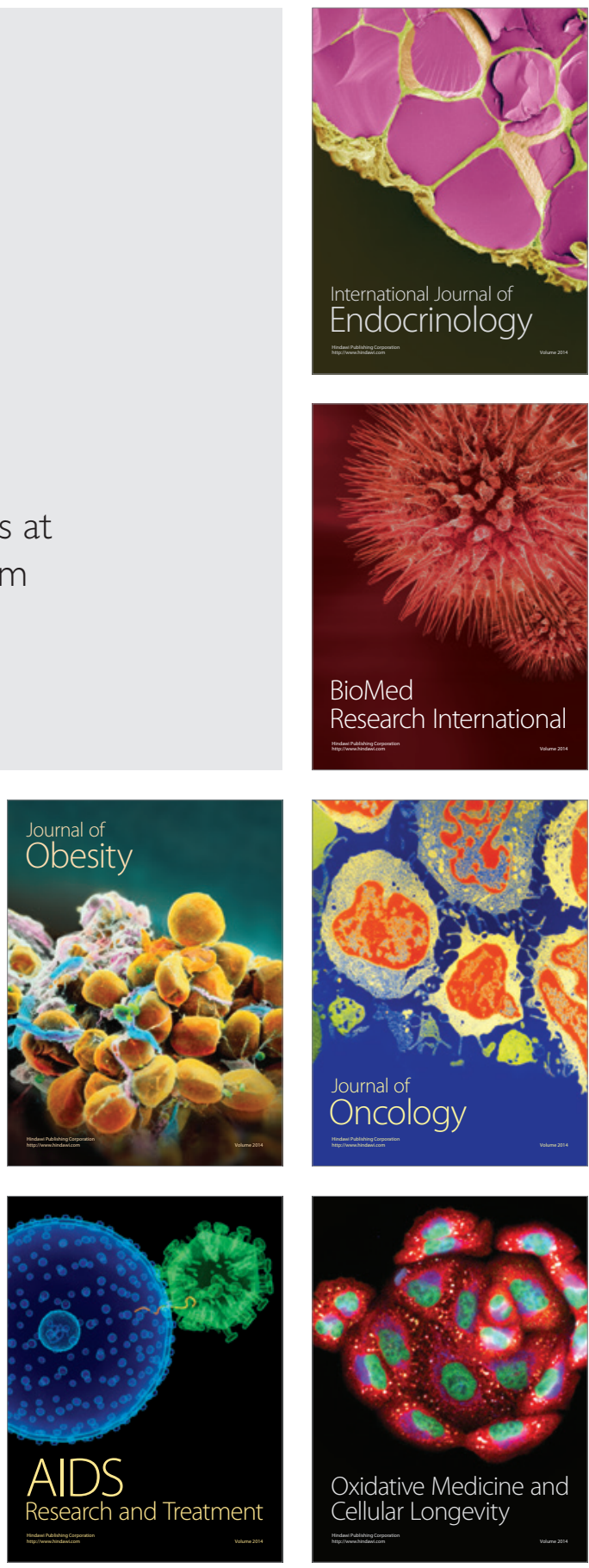